\title{
Correction to: Where do university graduates live? - a computer vision approach using satellite images
}

\section{David Koch $^{1} \cdot$ Miroslav Despotovic ${ }^{1} \cdot$ Simon Thaler $^{1}$ (D) $\cdot$ Matthias Zeppelzauer $^{2}$ (i)}

Published online: 11 May 2021

(C) Springer Science+Business Media, LLC, part of Springer Nature 2021

\section{Correction to: Applied Intelligence} https://doi.org/10.1007/s10489-021-02268-8

The original article unfortunately contained an error. The last name of the second author should be Despotovic instead of Dispotovic. The institution of Matthias Zeppelzauer was wrong and an ORCID needs to be added in his name.

The original article has been corrected.

Publisher's note Springer Nature remains neutral with regard to jurisdictional claims in published maps and institutional affiliations.

The online version of the original article can be found at https://doi.org/ 10.1007/s10489-021-02268-8

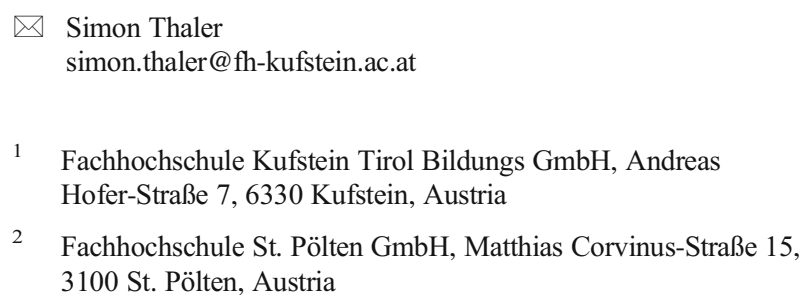

2 Fachhochschule St. Pölten GmbH, Matthias Corvinus-Straße 15, 3100 St. Pölten, Austria 